\title{
Multiple Approaches at Admission Based on Lung Ultrasound and Biomarkers Improves Risk Identification in COVID-19 Patients
}

\author{
Jorge Rubio-Gracia 1,2,*,+(D), Marta Sánchez-Marteles ${ }^{1,2,+}+^{(D}$, Vanesa Garcés-Horna ${ }^{1,2}$, Luis Martínez-Lostao ${ }^{2,3,4}$, \\ Fernando Ruiz-Laiglesia 1,2 (D), Silvia Crespo-Aznarez ${ }^{1}$ (D) Natacha Peña-Fresneda 2,4 (D), Borja Gracia-Tello 1,2,3, \\ Alberto Cebollada ${ }^{2,5}$, Patricia Carrera-Lasfuentes ${ }^{2,6}$, Juan Ignacio Pérez-Calvo ${ }^{1,2,4,7}$ (D) \\ and Ignacio Giménez-López ${ }^{2,4,7}$ (D)
}

check for updates

Citation: Rubio-Gracia, J.;

Sánchez-Marteles, M.; Garcés-Horna,

V.; Martínez-Lostao, L.;

Ruiz-Laiglesia, F.; Crespo-Aznarez, S.;

Peña-Fresneda, N.; Gracia-Tello, B.;

Cebollada, A.; Carrera-Lasfuentes,

P.; et al. Multiple Approaches at

Admission Based on Lung

Ultrasound and Biomarkers Improves

Risk Identification in COVID-19

Patients. J. Clin. Med. 2021, 10, 5478.

https://doi.org/10.3390/jcm10235478

Academic Editor: Giovanni Frisullo

Received: 20 October 2021

Accepted: 18 November 2021

Published: 23 November 2021

Publisher's Note: MDPI stays neutral with regard to jurisdictional claims in published maps and institutional affiliations.

Copyright: (c) 2021 by the authors. Licensee MDPI, Basel, Switzerland. This article is an open access article distributed under the terms and conditions of the Creative Commons Attribution (CC BY) license (https:// creativecommons.org/licenses/by/ $4.0 /)$.
1 Internal Medicine Department, Clinical Hospital “Lozano Blesa”, 50009 Zaragoza, Spain; marta.sanchez15@yahoo.es (S.-M.M.); vanesa_garces@hotmail.com (G.-H.V.); fruizl@unizar.es (R.-L.F.); silviacrespoaz@gmail.com (C.-A.S.); bcgracia@salud.aragon.es (G.-T.B.); jiperez@unizar.es (P.-C.J.I.)

2 Aragon Health Research Institute, 50009 Zaragoza, Spain; lmartinezlos@salud.aragon.es (M.-L.L.); npfrosyoly@gmail.com (P.-F.N.); albertocebollada@hotmail.com (C.A.); pcarreralasfuentes@gmail.com (C.-L.P.); igimenez@unizar.es (G.-L.I.)

3 Immunology Department, Clinical Hospital "Lozano Blesa", 50009 Zaragoza, Spain

4 Center for Biomedical Research of Aragon, 50009 Zaragoza, Spain

5 Biocomputation Unit, Center for Biomedical Research of Aragon, 50009 Zaragoza, Spain

6 Biomedical Research Networking Center in Hepatic and Digestive Diseases (CIBERehd), 28005 Madrid, Spain

7 School Medicine, Zaragoza University, 50009 Zaragoza, Spain

* Correspondence: jorgerubiogracia@gmail.com

+ Both authors contributed equally to this manuscript.

Abstract: Background: Risk stratification of COVID-19 patients is fundamental to improving prognosis and selecting the right treatment. We hypothesized that a combination of lung ultrasound (LUZ-score), biomarkers (sST2), and clinical models (PANDEMYC score) could be useful to improve risk stratification. Methods: This was a prospective cohort study designed to analyze the prognostic value of lung ultrasound, sST2, and PANDEMYC score in COVID-19 patients. The primary endpoint was in-hospital death and/or admission to the intensive care unit. The total length of hospital stay, increase of oxygen flow, or escalated medical treatment during the first $72 \mathrm{~h}$ were secondary endpoints. Results: a total of 144 patients were included; the mean age was $57.5 \pm 12.78$ years. The median PANDEMYC score was 243 (52), the median LUZ-score was 21 (10), and the median sST2 was $53.1 \mathrm{ng} / \mathrm{mL}$ (30.9). Soluble ST2 showed the best predictive capacity for the primary endpoint $($ AUC $=0.764(0.658-0.871) ; p=0.001)$, towards the PANDEMYC score (AUC $=0.762(0.655-0.870)$; $p=0.001)$ and LUZ-score (AUC $=0.749(0.596-0.901) ; p=0.002)$. Taken together, these three tools significantly improved the risk capacity $(\mathrm{AUC}=0.840(0.727-0.953) ; p \leq 0.001)$. Conclusions: The PANDEMYC score, lung ultrasound, and sST2 concentrations upon admission for COVID-19 are independent predictors of intra-hospital death and/or the need for admission to the ICU for mechanical ventilation. The combination of these predictive tools improves the predictive power compared to each one separately. The use of decision trees, based on multivariate models, could be useful in clinical practice.

Keywords: lung ultrasound; COVID-19; ST-2

\section{Introduction}

Severe acute respiratory syndrome coronavirus type 2 (SARS-CoV-2) causes COVID-19 disease [1,2]. This infectious disease is capable of causing multi-organic involvement $[3,4]$, bilateral viral pneumonia, and sometimes, early respiratory distress syndrome in adults (ARDS), with the need for mechanical ventilation in about $8 \%$ of total COVID-19 hospitalizations $[2,5]$. 
COVID-19 pathophysiology has several well-differentiated phases [2]. During the first week, a viral picture occurs that later gives way to a pro-inflammatory state [3], influenced by cytokine storm and thrombotic phenomena [6]. This situation can last for months in some cases, which is called post-COVID-19 syndrome [7,8]. Because of this unusual evolution for an infectious disease [2], sometimes, clinicians find it difficult to identify patients at higher risk of admission or in need of early intensive care [1]. Therefore, the availability of clinical tools to stratify risk and design specific diagnostic-therapeutic strategies is essential to improve outcomes.

Risk-stratification tools for COVID-19 were initially based on the analysis of baseline clinical characteristics through retrospective cohort studies during the first pandemic wave $[1,9]$. As we gathered greater knowledge about the disease and clinical experience accumulated $[5,6,8]$, research and practice moved from clinical data to more complex analysis based on biomarkers [10-13], imaging [14,15], or functional study of the main affected organs [16].

We have previously shown the predictive value of lung ultrasound (LUS) [17] and biochemical biomarkers [18]. Now we aim at developing a multidimensional approach for risk stratification in COVID-19 patients. Our hypothesis is that the addition of lung ultrasound and laboratory biomarkers to a proven clinical score (PANDEMYC score) [9] increases its predictive ability to detect worse outcomes.

\section{Materials and Methods}

\subsection{Study Design}

This is a unicenter, prospective study carried out between July and October 2020 in the Infectious Diseases and Internal Medicine service of a tertiary university hospital. Inclusion and exclusion criteria have been previously published [17]. In summary, they were patients admitted with confirmed COVID-19 infection, respiratory symptoms, stable from the respiratory point of view (without requiring initial admission to the ICU or mechanical ventilation), and without advanced cognitive impairment. Exclusion criteria were (1) previous intensive care unit (ICU) admission; (2) refusal of the patient to participate; (3) functional dependence (Barthel index < 50 points); (4) moderate/severe cognitive impairment (Pfeiffer scale); (5) advanced COPD (forced expiratory volume in $1 \mathrm{~s}<30 \%$ ) or a history of emphysema and/or pulmonary fibrosis; or (6) active cáncer.

During the first $72 \mathrm{~h}$ of admission, vital signs were recorded. Estimated PAFI (oxygen saturation $/ \mathrm{FiO}_{2}$ supplied) and Borg scale were used as indirect markers of respiratory function. The assessment was complemented with routine blood tests $(\mathrm{CBC}$, biochemistry, coagulation, and gas tests). Additional blood samples were collected with patient consent and stored at $-80^{\circ} \mathrm{C}$ in the Biobank of the Aragon Health Research Institute (IIS Aragon) until analysis.

\subsection{Risk Prediction through Basic Clinical and Analytical Parameters}

PANDEMYC score [9] was selected as the reference predictive model in this study. It is a prediction model for COVID-19 patients, based on basic clinical and laboratory data at admission, that has been demonstrated to predict in-hospital death of COVID-19 patients [9]. This model was chosen based on the following arguments: first, its creation was based on a cohort of patients from our same country and with similar characteristics; second, score is calculated from nine variables that are easy to obtain in routine clinical practice, even if some of them are missing; and third, the tool shows excellent power in predicting a hard target such as in-hospital death $(\mathrm{AUC}=0.88)$ [9].

\subsection{Point-of-Care Lung Ultrasound and Biomarkers}

LUS was performed to identify and quantify lung damage caused by SARS-CoV-2 infection. LUS was developed following a previously described protocol [17]. We developed a lung injury score (LUZ-score) based on the recognition of four simple patterns 
(scoring from 0 to 4 ) in twelve different thoracic areas with a final score between 0 and 48 points [17].

Soluble ST-2 (sST2) was selected as an indirect biomarker for lung damage. Soluble ST2 determinations were carried out from serum aliquots previously inactivated for the SARS-CoV-2 virus with $1 \%$ Triton-X100. Serum SST2 was quantified by enzyme-linked immunosorbent assay (ELISA), following the instructions from the manufacturer (DY523B, R\&D Systems Europe Ltd., Minneapolis, MN, USA).

\subsection{Primary and Secondary Outcomes}

In-hospital death from any cause and/or the need for admission to the ICU for the administration of mechanical ventilation was selected as the primary endpoint. Secondary endpoints were: (1) need to increase $\mathrm{O}_{2}$ therapy during the first $72 \mathrm{~h}$. (2) Need to increase medical treatment (increase initial corticosteroids dose, add remdesivir or other biological therapies) during the first $72 \mathrm{~h}$. (3) Length of hospital stay in those patients who did not reach primary endpoint. (4) Combined endpoint including need to increase $\mathrm{O}_{2}$ or COVID-19 therapy during the first $72 \mathrm{~h}$ after admission.

\subsection{Statistical Analysis}

An initial descriptive analysis of all clinical variables was carried out. Continuous variables are reported as mean with standard deviation (SD) or median with interquartile range $(\mathrm{IQR})$, whereas qualitative variables are expressed as frequencies and percentages. The relationship between qualitative variables was evaluated with Chi-square $\left(\chi^{2}\right)$ test. Student $t$-test or Mann-Whitney $\mathrm{U}$ test was employed for comparing means of two independent groups, and ANOVA or Kruskal-Wallis test was used when the qualitative variable had more than two categories. Normality was tested using Kolmogorov-Smirnov test.

Logistic regression models were constructed, and odds ratios (ORs) and 95\% confidence intervals (CIs) were calculated. The discriminatory accuracy of models was evaluated using the area under the receiver operating characteristics (ROC) curve (AUC) or c-index [19]. Then, ROC curves were compared two by two [20]

Classification trees (CART) were constructed for predicting primary outcomes based on PANDEMYC score [9], point-of-care lung ultrasound (LUZ score) [17], and baseline sST2 concentrations. The rpart algorithm [21] was used for generating decisions trees. Pruning and tuning parameters were applied to optimize the predictive model by avoiding an over-complex tree and thus increase the model's accuracy. Ten-fold was used to estimate out-of-sample accuracy, given the constraint on data availability and avoiding over-fitting issue. To reduce variability, multiple rounds of cross-validation were performed using different partitions, and validation results were combined over rounds to estimate model's performance [22].

For all tests, a two-sided $p<0.05$ was considered statistically significant. Statistical analysis was carried out with Statistical Package for the Social Sciences (SPSS, version 24.0 for Windows. IBM Corp., Armonk, NY, USA). CART was constructed with caret library from R package (Version 6.0-88) and rpart2 algorithm (Max Kuhn (2021)).

The study was approved by the regional research ethics committee (CEICA, Ref. PI20/248, 13 May 2020) and met the basic requirements of the ethics guidelines of Helsinki Declaration.

\section{Results}

\subsection{Baseline Characteristics}

From the 151 patients initially recruited, 144 patients were finally included (seven blood samples were not available for ELISA). The mean age was $57.5 \pm 12.78$ years, and $60.4 \%$ were males. Comorbidities with higher prevalence were hypertension (37.5\%), smoking $(33.6 \%)$, dyslipidemia or previous statins treatment $(29.2 \%)$, and diabetes $(17.4 \%)$. (Table 1$)$. 
Table 1. Baseline characteristics according to PANDEMYC score (tertiles) at admission.

\begin{tabular}{|c|c|c|c|c|c|}
\hline Variable & TOTAL & $\begin{array}{c}p<25 \\
(<214 \text { Points) }\end{array}$ & $\begin{array}{c}p 25 \text { to } 75 \\
\text { (214-266 Points) }\end{array}$ & $\begin{array}{c}p>75 \\
(>266 \text { Points) }\end{array}$ & $p$-Value \\
\hline Total size $(\mathrm{N})$ & 144 & & & & \\
\hline Age (years) * & $57.5 \pm 12.8$ & $42.7 \pm 9.2$ & $59.6 \pm 9.3$ & $68.1 \pm 7.9$ & $<0.001$ \\
\hline Gender-Male (n (\%)) & $87(60.4)$ & $21(58.3)$ & $42(58.3)$ & $24(66.7)$ & 0.471 \\
\hline Duration of symptom (days) & $6.5 \pm 3.3$ & $6.6 \pm 3.3$ & $6.6 \pm 3.3$ & $6.0 \pm 3.3$ & 0.677 \\
\hline $\begin{array}{l}\text { Time until COVID-19 } \\
\text { confirmation (Days) }\end{array}$ & $3(7)$ & $2(6)$ & $3(7)$ & $3(8)$ & 0.832 \\
\hline \multicolumn{6}{|l|}{ Comorbidities (n (\%)): } \\
\hline - Hypertension & $54(37.5)$ & $4(11.1)$ & $28(38.9)$ & $22(61.1)$ & $<0.001$ \\
\hline - Heart failure & $4(2.8)$ & $0(0.0)$ & $1(1.4)$ & $3(8.3)$ & 0.033 \\
\hline - Dyslipidemia & $42(29.2)$ & $7(19.4)$ & $15(20.8)$ & $20(55.6)$ & 0.001 \\
\hline - Coronary artery disease & $5(3.5)$ & $1(2.8)$ & $3(4.2)$ & $1(2.8)$ & 1.000 \\
\hline - Diabetes & $25(17.4)$ & $2(5.6)$ & $17(23.6)$ & $6(16.7)$ & 0.215 \\
\hline - History of smoking * & $48(33.6)$ & $6(16.7)$ & $26(36.1)$ & $16(45.7)$ & 0.010 \\
\hline - COPD/Asthma & $16(11.1)$ & & & & \\
\hline - Atrial/flutter fibrillation & $5(3.6)$ & $0(0.0)$ & $2(2.9)$ & $3(8.3)$ & 0.059 \\
\hline - CKD & $7(4.9)$ & $1(2.8)$ & $1(1.4)$ & $5(13.9)$ & 0.029 \\
\hline \multicolumn{6}{|l|}{ Clinical variables } \\
\hline - $\mathrm{BMI}\left(\mathrm{Kgs} / \mathrm{m}^{2}\right)$ & $28.9(6.4)$ & $30.2(7.8)$ & $29.1(6.6)$ & $28.2(4.9)$ & 0.568 \\
\hline - SBP (mmHg) & $126.9 \pm 16.7$ & $124.6 \pm 15.3$ & $126.2 \pm 17.9$ & $130.5 \pm 15.1$ & 0.301 \\
\hline - DBP (mmHg) & $77.2 \pm 10.9$ & $76.9 \pm 11.4$ & $76.5 \pm 10.8$ & $79.2 \pm 10.5$ & 0.480 \\
\hline • HR (bpm) & $80.9 \pm 12.8$ & $83.1 \pm 13.7$ & $80.0 \pm 13.4$ & $80.5 \pm 10.4$ & 0.490 \\
\hline - Estimated PAFI (mmHg) & $367(92)$ & $429(74)$ & $403(94)$ & $340(76)$ & 0.001 \\
\hline - Borg scale for dyspnea (points) & $4(6)$ & $5(6)$ & $5(4)$ & $4(5)$ & 0.844 \\
\hline \multicolumn{6}{|l|}{ Laboratory: } \\
\hline - Urea (mg/dL) & $33(19)$ & $28(16)$ & $31(14)$ & $40(23)$ & 0.002 \\
\hline - Creatinine $(\mathrm{mg} / \mathrm{dL}) *$ & $0.94(0.29)$ & $0.82(0.26)$ & $0.89(0.28)$ & $1.05(0.51)$ & $<0.001$ \\
\hline Variable (Continue) & TOTAL & $p<25$ & $p 25$ to 75 & $p>75$ & $p$-Value \\
\hline \multicolumn{6}{|l|}{ Laboratory: } \\
\hline - Aspartate transaminase (U/L) & $37(27)$ & $38(48)$ & $34(20)$ & $41(21)$ & 0.338 \\
\hline - Alanine transaminase (U/L) & $31(28)$ & $40(56)$ & $31(20)$ & $28(25)$ & 0.175 \\
\hline - Creatin phophokinase (U/L) & $94(92)$ & $103(116)$ & $83(63)$ & $129(92)$ & 0.048 \\
\hline - Lactate deshidrogenase (U/L) & $306(145)$ & $282(94)$ & $306(114)$ & $369(202)$ & 0.007 \\
\hline - C-Reactive Protein $(\mathrm{mg} / \mathrm{L})$ * & $63(81)$ & $38(77)$ & $53(70)$ & $91(98)$ & 0.002 \\
\hline - Ferritin (ng/mL) & $707(908)$ & $682(917)$ & $710(914)$ & $699(1022)$ & 0.666 \\
\hline - Hemoglobin $(\mathrm{g} / \mathrm{dL})^{*}$ & $14.2 \pm 1.5$ & $14.3 \pm 1.1$ & $14.2 \pm 1.6$ & $14.1 \pm 1.7$ & 0.707 \\
\hline - Total leucocytes $(\times 1000)$ & $5.6(3.1)$ & $5.0(1.9)$ & $5.8(3.6)$ & $6.1(3.1)$ & 0.407 \\
\hline - Total lymphocytes $(\times 1000)$ * & $0.9(0.7)$ & $1.1(0.6)$ & $1.0(0.6)$ & $0.7(0.5)$ & 0.019 \\
\hline - Total platelets $(\times 1000)^{*}$ & $173(100)$ & $189(75)$ & $176(118)$ & $147(87)$ & 0.016 \\
\hline - D-Dimer (ng/mL) & $688(633)$ & $664(560)$ & $654(519)$ & $802(820)$ & 0.195 \\
\hline - Fibrinogen $(\mathrm{mg} / \mathrm{dL})$ & $775(208)$ & $783(193)$ & $763(212)$ & $779(243)$ & 0.976 \\
\hline - Interleukine-6 (pg/mL) & $40(30)$ & $39(27)$ & $29(31)$ & $50(57)$ & 0.041 \\
\hline - sST2 (ng/L) & $53.1(30.9)$ & $49.3(24.9)$ & $50.8(32.0)$ & $62.1(36.6)$ & 0.060 \\
\hline
\end{tabular}


Table 1. Cont.

\begin{tabular}{|c|c|c|c|c|c|}
\hline Variable & TOTAL & $\begin{array}{c}p<25 \\
(<214 \text { Points) }\end{array}$ & $\begin{array}{c}p 25 \text { to } 75 \\
\text { (214-266 Points) }\end{array}$ & $\begin{array}{c}p>75 \\
(>266 \text { Points) }\end{array}$ & $p$-Value \\
\hline X-rays (n (\%)) & & & & & 0.192 \\
\hline - Normal & $25(17.9)$ & $8(22.9)$ & $12(16.9)$ & $5(14.7)$ & \\
\hline - Unilateral consolidation & $35(25.0)$ & $9(25.7)$ & $20(28.2)$ & $6(17.6)$ & \\
\hline - Bilateral consolidations & $80(57.1)$ & $18(51.4)$ & $39(54.9)$ & $23(67.6)$ & \\
\hline Lung ultrasound (LUZ-score) & $21(10)$ & $18(12)$ & $21(10)$ & $22(10)$ & 0.024 \\
\hline \multicolumn{6}{|l|}{ Therapies (n (\%)) } \\
\hline - Colchicine & $10(6.9)$ & $4(11.1)$ & $4(5.6)$ & $2(5.6)$ & 0.525 \\
\hline - Remdesivir & $46(31.9)$ & $10(27.8)$ & $18(25.0)$ & $18(50.0)$ & 0.026 \\
\hline - Systemic corticosteroids & $113(78.5)$ & $28(77.8)$ & $52(72.2)$ & $33(91.7)$ & 0.153 \\
\hline $\begin{array}{l}\text { - Medium dose of corticosteroids } \\
\text { (Dexametasone }(\mathrm{mg}) \text { ) }\end{array}$ & $6(3)$ & $6(0)$ & $6(3)$ & $6(3)$ & 0.156 \\
\hline
\end{tabular}

* Variables included in PANDEMYC score.

\subsection{Characteristics according to the PANDEMYC Score at Admission}

The PANDEMYC score median was 243 points (52). Patients with the highest PANDEMYC score (over 75 percentile, $>266$ points) were older, with a higher prevalence of comorbidities such as hypertension, heart failure, or chronic kidney disease (CKD). Creatinin-phosphokinase (CPK), lactate deshidrogenase (LDH), C-reactive protein (CRP), or Interleuquin-6 (IL-6) concentrations were significantly higher among those patients over 75 percentile. Soluble ST2 concentrations were also higher in this group, although significance was not reached. Patients with a PANDEMYC score over the percentile of 75 also showed a higher rate of lung injury by LUS or estimated PAFI (Table 1).

\subsection{Outcomes and Multivariable Logistic Regression Model}

The primary endpoint (in-hospital death and/or admission to ICU after the first $72 \mathrm{~h}$ of admission) was reached in 15 patients (10.4\%). One patient died in the ICU, and fourteen were transferred to ICU for mechanical ventilation. The median length of stay in those patients who did not reach the primary endpoint was 7 days (5). An increase in oxygen supply during the first $72 \mathrm{~h}$ after admission was administered to $34.1 \%$ of patients, and almost $40 \%$ needed an update in medical COVID-19 therapy (either increasing intravenous dexamethasone dose or adding new medical treatments). (Supplementary Table S1).

The primary endpoint was significantly higher among those patients with a PANDEMYC score $>75$ percentile $(22.2 \%$ vs. $6.5 \% ; p=0.012)$, as was the need to increase $\mathrm{O}_{2}$ therapy during the first $72 \mathrm{~h}(53.8 \%$ vs. $25.0 \% ; p=0.005)$. The length of stay was also longer among this group (11 days vs. 7 days; $p \leq 0.001$ ) (Supplementary Table S1).

The PANDEMYC score and LUS and SST2 concentrations at admission were identified as independent predictors for the primary endpoint in univariable logistic regression analysis (Table 2). When comparing predictive capacity, SST2 showed very similar values (AUC $=0.764(0.658-0.871) ; p=0.001)$, as PANDEMYC score $(\mathrm{AUC}=0.762(0.655-0.870)$; $p=0.001)$ and LUS (LUZ-score) (AUC $=0.749(0.596-0.901) ; p=0.002)$ (Figure 1). However, the combination of these three diagnostic tools (PANDEMYC, lung ultrasound and sST2) in a multivariable logistic regression model significantly improved the predictive risk capacity (AUC $=0.838(0.716-0.961) ; p \leq 0.001)$. The addition of gender to the model did not cause any further gain (AUC $=0.840(0.727-0.953) ; p \leq 0.001)$ (Figure 1 and Supplementary Table S2). 
Table 2. Univariable and multivariable logistic regression analysis for the primary endpoint (in-hospital death and/or need for ICU admission for mechanical ventilation).

\begin{tabular}{cccccc}
\hline & Univariable & & \multicolumn{3}{c}{ Multivariable } \\
\hline Variable & OR (CI 95\%) & $p$-Value & Variable & OR (CI 95\%) & $p$-Value \\
\hline $\begin{array}{c}\text { PANDEMYC score } \\
\text { (points) }\end{array}$ & $1.03(1.01-1.05)$ & $\mathbf{0 . 0 0 2}$ & $\begin{array}{c}\text { PANDEMYC score } \\
\text { (points) }\end{array}$ & $1.02(1.01-1.04)$ & $\mathbf{0 . 0 3 4}$ \\
\hline sST2 $(\mathrm{ng} / \mathrm{mL})$ & $1.02(1.01-1.03)$ & $\mathbf{0 . 0 1 6}$ & sST2 (ng/mL) & $1.02(1.01-1.03)$ & $\mathbf{0 . 0 3 8}$ \\
\hline $\begin{array}{c}\text { LUZ-score } \\
\text { (points) }\end{array}$ & $1.13(1.04-1.22)$ & $\mathbf{0 . 0 0 4}$ & $\begin{array}{c}\text { LUZ-score } \\
\text { (points) }\end{array}$ & $1.12(1.02-1.22)$ & $\mathbf{0 . 0 1 4}$ \\
\hline
\end{tabular}

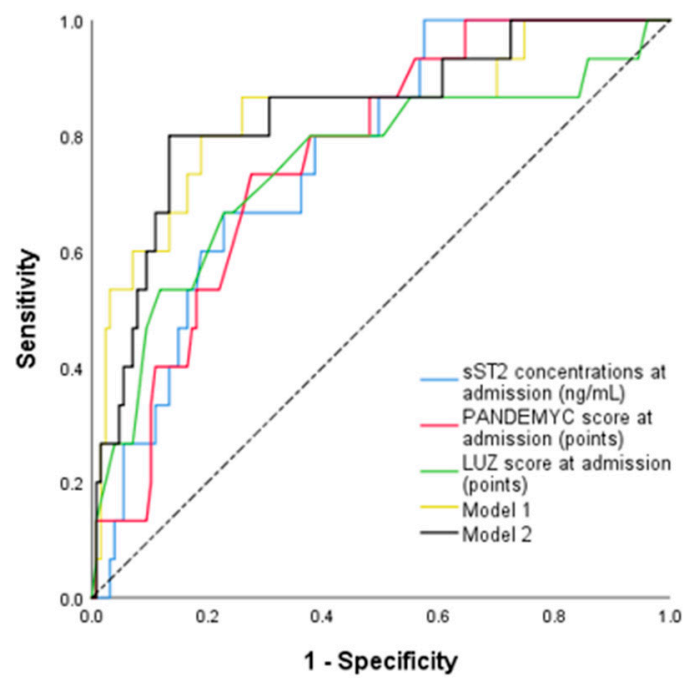

\begin{tabular}{|l|c|c|}
\hline Variable & AUC (CI 95\%) & p-Value \\
\hline sST2 concentrations at admission (ng/mL) & $0.764(0.658-0.871)$ & $\mathbf{0 . 0 0 1}$ \\
\hline PANDEMYC score at admission (points) & $0.762(0.655-0.870)$ & $\mathbf{0 . 0 0 1}$ \\
\hline Lung ultrasound Zaragoza score (LUZ score) at & $0.749(0.596-0.901)$ & $\mathbf{0 . 0 0 2}$ \\
admission & & \\
\hline Model $1 \dagger$ & $0.838(0.716-0.961)$ & $<\mathbf{0 . 0 0 1}$ \\
\hline Model $2 \ddagger$ & $0.840(0.727-0.953)$ & $<\mathbf{0 . 0 0 1}$ \\
\hline
\end{tabular}

\footnotetext{
$\dagger$ Model 1 includes SST2 + PANDEMYC score + Lung ultrasound Zaragoza score

+ Model 2 includes SST2 + PANDEMYC score + Lung ultrasound Zaragoza score + Gender
}

Figure 1. Receiver operating characteristic curves of the different models analyzed.

\subsection{Decision Diagrams Based on Classification Trees}

We propose two different predictive risk models for the primary endpoint, from statistical simulation and taking into account the previously mentioned prediction tools (PANDEMYC score, point of care lung ultrasound, and baseline sST2 concentrations).

The first model includes an initial evaluation by LUS. If LUZ-score is equal to or below 29 points, the probability of achieving the primary endpoint is $6 \%$. However, if LUS involvement is significant at admission (above 29 points), the model suggests a second evaluation with a PANDEMYC score to assess risk. In this case, if this value is higher than 263 points, the probability of developing the primary endpoint is $54 \%$, with a sensitivity of $46.7 \%$ and a specificity of $95 \%(\mathrm{AUC}=0.723$ ) (Figure $2 \mathrm{~A})$. 


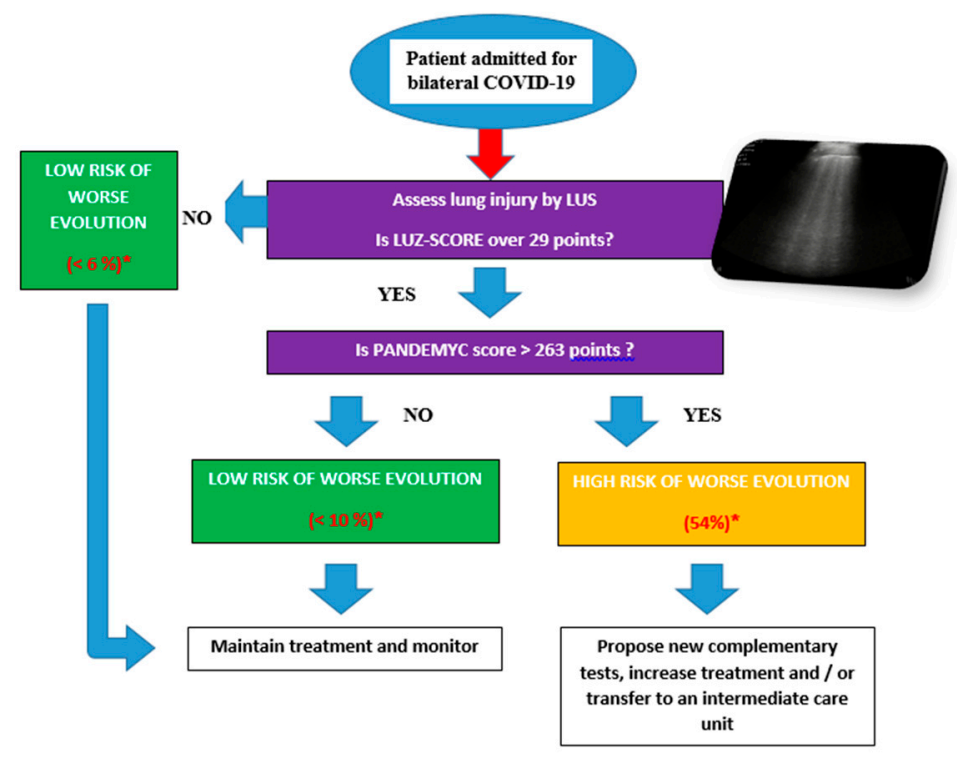

* Red letters show the probability of reaching primary end-point Sensitibity $\mathbf{4 6 . 7 \%}$, Specificity $95.3 \%$; $\mathrm{AUC}=0.723$

(A)

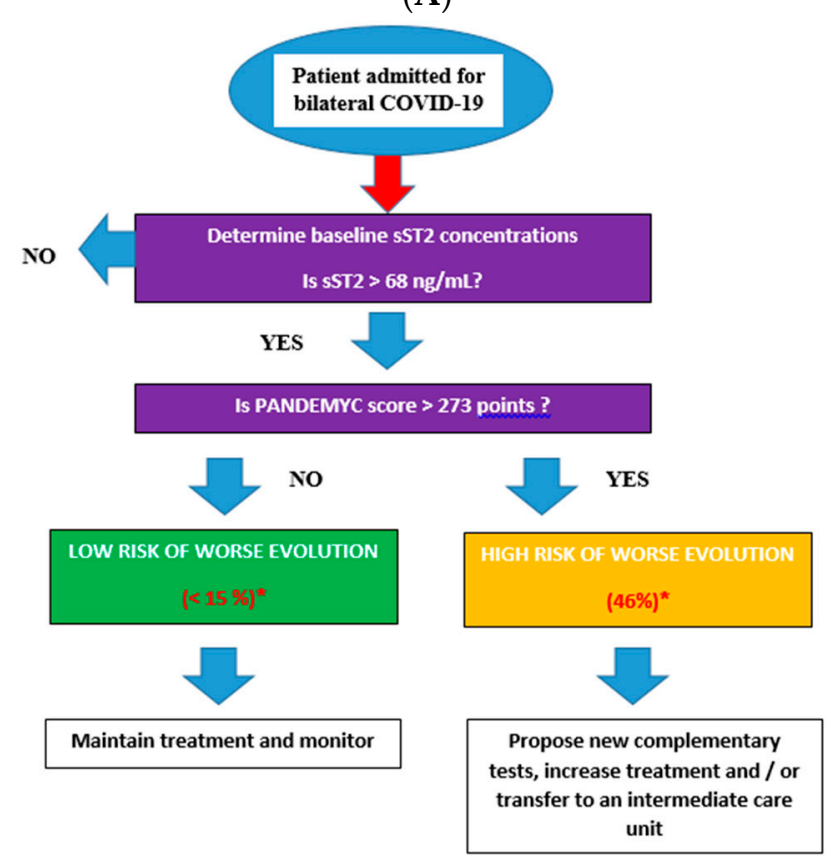

* Red letters show the probability of reaching primary end-point.

Sensitibity $66.7 \%$, Specificity $77.2 \%$; AUC $=0.752$

(B)

Figure 2. (A): Decisions diagrams proposed based on LUZ-score and PANDEMYC score. (B): Decisions diagrams proposed based on sST2 and PANDEMYC score.

The second model suggests an initial assessment of sST2 concentrations. If SST2 is lower than $68 \mathrm{ng} / \mathrm{mL}$, the probability of reaching the primary endpoint is $5 \%$. However, if baseline sST2 is higher than $68 \mathrm{ng} / \mathrm{mL}$, the model suggests a second evaluation with a PANDEMYC score (cut-off 273 points). If sST2 is higher than $68 \mathrm{ng} / \mathrm{mL}$, and the PANDEMYC score is $>273$ points, the probability of reaching the primary endpoint is $54 \%$ (Sensibility $66.7 \%$, Specificity $77.2 \%$; AUC $=0.752$ ) (Figure $2 B$ ). 


\section{Discussion}

In this study, we validated the PANDEMYC score for the primary endpoint of inhospital death and/or ICU admission during the first $72 \mathrm{~h}$. Furthermore, we confirmed our initial hypothesis, showing that a multimodal assessment, based on biomarkers (sST2), LUS (LUZ-score), and PANDEMYC score, improves the risk-predictive capacity of each marker alone. The creation of a decision tree that combines clinical data, LUS, and biomarkers (sST2) in COVID-19 patients is unprecedented.

Identifying patients who may present serious complications after being admitted for COVID-19 is vital to improve the patient's prognosis. Since COVID-19 started, several scoring scales as CURB-65, ISARIC [23], or pneumonia score index (PSI) have been validated for in-hospital death outcomes [24]. However, given that COVID-19 is a novel disease, having specific tools to improve clinical care is essential.

In our analysis, the PANDEMYC score [9] is able to identify a population with a higher prevalence of comorbidities and pro-inflammatory status inferred through a significant increase in concentrations of CPK, LDH, CRP, or lymphopenia (Table 1). In addition, IL-6 and sST2 concentrations were also higher in the group of patients with a higher PANDEMYC score, data that would confirm the implication of interleukins in the prognosis of patients. However, our results show that the predictive capacity of the PANDEMYC score is lower than previously described, probably because we selected a combined primary endpoint instead of a harder endpoint as in-hospital death alone, but also because our sample size was limited. That is why our study aims to improve the predictive capacity of the PANDEMYC score, providing objective tools such as lung ultrasound or novel biomarkers in this field.

LUS has been demonstrated to be useful to detect patients with worse outcomes $[14,15,17,25,26]$ with similar accuracy as computed tomography [27]. According to our results, the predictive power of LUS (LUZ-score) [17] for the primary endpoint is similar to the PANDEMYC score (AUC 0.749 vs. AUC 0.762; $p=0.869$ ). However, LUS has some disadvantages, as results can differ between observers or a high sensitivity but low specificity [17], a situation that can be explained given that pattern recognition (b lines), is common to other diseases, such as heart failure [28]. This argument makes a point of LUS as an ideal screening test, but with a high rate of false positives when trying to predict hard outcomes. Therefore, our proposal to combine prediction tools to increase statistical power seems reasonable.

Specifically, in this study, we propose to complement the PANDEMYC score and LUS with a novel biomarker that has been linked to lung injury in COVID-19 during admission (sST2). Soluble ST2 is the interleukin 33 (IL-33) receptor, and its concentrations have been associated with inflammatory phenomena and acute lung damage in processes of noncardiogenic origin [29]. Since lung tissue is the most important target for SARS-CoV-2 [30], sST2 has been tested as a novel predictive biomarker in COVID-19 [18,31]. In our analysis, sST2 was the strongest predictor for the primary endpoint, on top of the PANDEMYC score and point-of-care lung ultrasound. (Figure 1, Table 2, and Supplementary Table S2). Now, since it is a biomarker also related to other processes-mainly heart failure [32,33] and myocardial involvement [34] —SST2 concentrations must be interpreted with caution in patients with COVID-19 because myocardial affection produced by COVID-19 [35] could increase basal levels of sST2. Furthermore, sST2 concentrations might change according to diurnal variation in some patients, and that situation should also be considered [36].

In summary, the combination of these three tests (PANDEMYC score, point-of-care lung ultrasound, and SST2 concentrations) is superior in improving the ability to predict risk at admission in patients with COVID-19 (Figure 1, Table 2, and Supplementary Table S2). These results are novel and could be transferred to routine clinical practice once validated or even lay the basis for clinical trials to standardize treatment based on objective data. Furthermore, our models consider as a primary objective not only mortality but also the need to enter the ICU for mechanical ventilation. This is an added value, especially if we take into account the AUCs reached (Table 2 and Supplementary Table S2). Most of 
the predictive models in which clinical variables [9] or lung ultrasound [37,38] are used only contemplate mortality as the primary outcome, when identifying those patients who require early intubation is probably more practical to improve care, and this fact makes our models more attractive.

In an attempt to make an approach to clinical practice, we propose two decision algorithms based on the creation of statistical multivariable models (Figure 2A,B). Both models propose an initial screening either with LUS or with sST2 and subsequently a second evaluation with the PANDEMYC score to identify patients at higher risk with similar results (Figure 2A,B). The simulation did not find an additional improvement of the prediction by combining the three variables to generate a decision tree, so both models (considering two of the three predictive tools analyzed) can be used indistinguishably. Selecting one or another model should be based on several factors. A patient with acute heart failure or a history of interstitial lung disease is likely to benefit more from a biomarker-based model (sST2), as a lung ultrasound could be biased. However, predictive models based on soluble biomarkers are more expensive, and they require having such a laboratory technique, which is not always available.

\section{Limitations}

The results have been obtained from a single center and therefore cannot be extrapolated. Although clinical characteristics in our cohort were concordant with published data from other studies around the world and in our country $[17,18]$, external validation is necessary to determine a prediction model's reproducibility and generalizability to new and different patients. The sample size of the study was calculated based on the number of blood samples needed to analyze the sST2, and therefore the power of the multivariate model could have been underestimated. Lung ultrasound is a person-dependent technique, and therefore this fact could affect the final result. Finally, the decision trees have been elaborated from statistical models and would need to be validated in a different cohort.

\section{Conclusions}

PANDEMYC score, lung ultrasound, and SST2 concentrations upon admission for COVID-19 are independent predictors of intra-hospital death and/or the need for admission to the ICU for mechanical ventilation. The combination of these predictive tools improves the predictive power compared to each one separately. The use of decision trees, based on multivariate models, could be useful in clinical practice.

Supplementary Materials: The following are available online at https:/ / www.mdpi.com/article/ 10.3390/jcm10235478/s1, Table S1: Outcomes by PANDEMYC score at baseline, Table S2: Receiver operating characteristic curves comparison.

Author Contributions: Conceptualization, R.-G.J. S.-M.M., P.-C.J.I. and G.-L.I.; methodology, R.-G.J., S.-M.M., P.-C.J.I. and G.-L.I.; formal analysis, R.-G.J., C.A. and C.-L.P.; investigation, G.-H.V., R.-L.F., P.-F.N., C.-A.S., G.-T.B. and G.-L.I.; writing —original draft preparation, R.-G.J., M.-L.L., G.-L.I. and C.-L.P.; writing - review and editing, R.-G.J.; visualization, R.-G.J.; supervision, C.-L.P. All authors have read and agreed to the published version of the manuscript.

Funding: The study was funded through a COVID-19 2020 crowdfunding campaign launched by the Aragon Health Research Institute (https: / / www.iisaragon.es/utilidad-de-la-ecografia-clinica-yeluso-de-biomarcadores-sericos-en-la-estratificacion-del-riesgo-de-pacientes-con-infeccionpor-SARSCoV-2-COVID-19/, accessed on 20 October 2021).

Institutional Review Board Statement: The study was conducted according to the guidelines of the Declaration of Helsinki and approved by the regional research ethics committee (CEICA, Ref. PI20/248, 13 May 2020), and met the basic requirements of the ethics guidelines of Helsinki declaration.

Informed Consent Statement: Written informed consent was obtained from the patient(s) to publish this paper.

Conflicts of Interest: The authors declare no conflict of interest. 


\section{References}

1. Ramanathan, K.; Antognini, D.; Combes, A.; Paden, M.; Zakhary, B.; Ogino, M.; Maclaren, G.; Brodie, D. Clinical features of patients infected with 2019 novel coronavirus in Wuhan, China. Lancet 2020, 395, 497-506.

2. Guan, W.; Ni, Z.; Hu, Y.; Liang, W.; Ou, C.; He, J.; Liu, L.; Shan, H.; Lei, C.; Hui, D.S.C.; et al. Clinical Characteristics of Coronavirus Disease 2019 in China. N. Engl. J. Med. 2020, 382, 1708-1720. [CrossRef]

3. Chen, R.; Lan, Z.; Ye, J.; Pang, L.; Liu, Y.; Wu, W.; Qin, X.; Guo, Y.; Zhang, P. Cytokine Storm: The Primary Determinant for the Pathophysiological Evolution of COVID-19 Deterioration. Front. Immunol. 2021, 12, 589095. [CrossRef]

4. Darif, D.; Hammi, I.; Kihel, A.; El Idrissi Saik, I.; Guessous, F.; Akarid, K. The pro-inflammatory cytokines in COVID-19 pathogenesis: What goes wrong? Microb. Pathog. 2021, 153, 104799. [CrossRef]

5. Stenmark, K.R.; Frid, M.G.; Gerasimovskaya, E.; Zhang, H.; McCarthy, M.K.; Thurman, J.M.; Morrison, T.E. Mechanisms of SARS-CoV-2-induced lung vascular disease: Potential role of complement. Pulm. Circ. 2021, 11, 20458940211015799. [CrossRef] [PubMed]

6. Fahmy, O.H.; Daas, F.M.; Salunkhe, V.; Petrey, J.L.; Cosar, E.F.; Ramirez, J.; Akca, O. Is Microthrombosis the Main Pathology in Coronavirus Disease 2019 Severity?-A Systematic Review of the Postmortem Pathologic Findings. Crit. Care Explor. 2021, 3, e0427. [CrossRef] [PubMed]

7. Carod-Artal, F.J. Post-COVID-19 syndrome: Epidemiology, diagnostic criteria and pathogenic mechanisms involved. Crit. Care Explor. 2021, 3, e0427.

8. Cabrera Martimbianco, A.L.; Pacheco, R.L.; Bagattini, Â.M.; Riera, R. Frequency, signs and symptoms, and criteria adopted for long COVID: A systematic review. Int. J. Clin. Pract. 2021, 75, e14357. [CrossRef]

9. Torres-Macho, J.; Ryan, P.; Valencia, J.; Pérez-Butragueño, M.; Jiménez, E.; Fontán-Vela, M.; Izquierdo-García, E.; Fernandez-Jimenez, I.; Álvaro-Alonso, E.; Lazaro, A.; et al. The PANDEMYC Score. An Easily Applicable and Interpretable Model for Predicting Mortality Associated With COVID-19. J. Clin. Med. 2020, 9, 3066. [CrossRef]

10. Arnold, D.T.; Attwood, M.; Barratt, S.; Morley, A.; Elvers, K.T.; McKernon, J.; Donald, C.; Oates, A.; Noel, A.; MacGowan, A.; et al. Predicting outcomes of COVID-19 from admission biomarkers: A prospective UK cohort study. Emerg. Med. J. 2021, 38, 543-548. [CrossRef]

11. Kaftan, A.N.; Hussain, M.K.; Algenabi, A.A.; Naser, F.H.; Enaya, M.A. Predictive value of c $\Downarrow$ reactive protein, lactate dehydrogenase, ferritin and D-Dimer levels in diagnosing COVID-19 patients: A retrospective study. Acta Inform. Medica. 2021, 29, 45-50. [CrossRef] [PubMed]

12. Matsumoto, S.; Kuroda, S.; Sano, T.; Kitai, T.; Yonetsu, T.; Kohsaka, S.; Torii, S.; Kishi, T.; Komuro, I.; Hirata, K.; et al. Clinical and Biomarker Profiles and Prognosis of Elderly Patients With Coronavirus Disease 2019 (COVID-19) With Cardiovascular Diseases and/or Risk Factors. Circ. J. 2021, 85, 921-928. [CrossRef]

13. Myhre, P.L.; Prebensen, C.; Jonassen, C.M.; Berdal, J.E.; Omland, T. SARS-CoV-2 Viremia is Associated with Inflammatory, But Not Cardiovascular Biomarkers, in Patients Hospitalized for COVID-19. J. Am. Heart Assoc. 2021, 10, e019756. [CrossRef] [PubMed]

14. Cappa, G.; Secco, G.; Nganso, A.; Ruzga, R.; Perlini, S. The Role of Lung Ultrasound in Low-Resource Settings during the Coronavirus (SARS-CoV-2) Pandemic. J. Ultrasound Med. 2021, 24. [CrossRef]

15. Lerchbaumer, M.H.; Lauryn, J.H.; Bachmann, U.; Enghard, P.; Fischer, T.; Grune, J.; Hegemann, N.; Khadzhynov, D.; Kruse, J.M.; Lehner, L.J.; et al. Point-of-care lung ultrasound in COVID-19 patients: Inter- and intra-observer agreement in a prospective observational study. Sci. Rep. 2021, 11, 10678. [CrossRef] [PubMed]

16. Mejía, F.; Medina, C.; Cornejo, E.; Morello, E.; Vásquez, S.; Alave, J.; Schwalb, A.; Málaga, G. Oxygen saturation as a predictor of mortality in hospitalized adult patients with COVID-19 in a public hospital in Lima, Peru. PLoS ONE 2020, 15, e0244171. [CrossRef]

17. Rubio-Gracia, J.; Giménez-López, I.; Garcés-Horna, V.; López-Delgado, D.; Sierra-Monzón, J.L.; Martínez-Lostao, L.; Josa-Laorden, C.; Ruiz-Laiglesia, F.; Pérez-Calvo, J.I.; Crespo-Aznarez, S.; et al. Point-of-care lung ultrasound assessment for risk stratification and therapy guiding in COVID-19 patients. A prospective non-interventional study. Eur. Respir. J. 2021, 58, 2004283. [CrossRef] [PubMed]

18. Sánchez-Marteles, M.; Rubio-Gracia, J.; Peña-Fresneda, N.; Garcés-Horna, V.; Gracia-Tello, B.; Martínez-Lostao, L.; CrespoAznárez, S.; Pérez-Calvo, J.I.; Giménez-López, I. Early measurement of blood sST2 is a good predictor of death and poor outcomes in patients admitted for COVID-19 infection. J. Clin. Med. 2021, 10, 3534. [CrossRef] [PubMed]

19. Harrell, F.E.; Califf, R.M.; Pryor, D.B.; Lee, K.L.; Rosati, R.A. Evaluating the Yield of Medical Tests. JAMA J. Am. Med. Assoc. 1982, 247, 2543-2546. [CrossRef]

20. Molodianovitch, K.; Faraggi, D.; Reiser, B. Comparing the areas under two correlated ROC curves: Parametric and non-parametric approaches. Biometrical. J. 2006, 48, 745-757. [CrossRef] [PubMed]

21. Linda, A.; Clark, D.P. Tree-Based Models. In Statistical Models in S, 1st ed.; Routledge: Oxfordshire, UK, $1992 ;$ p. 43.

22. Seni, G.; Elder, J.F. Ensemble Methods in Data Mining: Improving Accuracy through Combining Predictions. Synth. Lect. Data Min. Knowl. Discov. 2010, 2, 1-126. [CrossRef]

23. Knight, S.R.; Ho, A.; Pius, R.; Buchan, I.; Carson, G.; Drake, T.M.; Dunning, J.; Fairfield, C.J.; Gamble, C.; Green, C.A.; et al. Risk stratification of patients admitted to hospital with covid-19 using the ISARIC WHO Clinical Characterisation Protocol: Development and validation of the 4C Mortality Score. BMJ 2020, 370, m3339. [CrossRef] 
24. Hu, H.; Kong, W.; Yao, N.; Qiu, Y.; Yao, R. Prognostic value of three rapid scoring scales and combined predictors for the assessment of patients with coronavirus disease 2019. Nurs. Open 2021, 3. [CrossRef] [PubMed]

25. Huang, Y.; Wang, S.; Liu, Y.; Zhang, Y.; Zheng, C.; Zheng, Y.; Zhang, C.; Min, W.; Yu, M.; Hu, M. A preliminary study on the ultrasonic manifestations of peripulmonary lesions of non-critical novel coronavirus pneumonia (COVID-19). Res. Sq. 2020, 10-24. [CrossRef]

26. Castelao, J.; Graziani, D.; Soriano, J.B.; Izquierdo, J.L. Findings and Prognostic Value of Lung Ultrasound in COVID-19 Pneumonia. J. Ultrasound Med. 2021, 40, 1315-1324. [CrossRef]

27. Tung-Chen, Y.; Martí de Gracia, M.; Díez-Tascón, A.; Alonso-González, R.; Agudo-Fernández, S.; Parra-Gordo, M.L.; Ossaba-Vélez, S.; Rodríguez-Fuertes, P.; Llamas-Fuentes, R. Correlation between Chest Computed Tomography and Lung Ultrasonography in Patients with Coronavirus Disease 2019 (COVID-19). Ultrasound Med. Biol. 2020, 46, 2918-2926. [CrossRef]

28. Pivetta, E.; Goffi, A.; Nazerian, P.; Castagno, D.; Tozzetti, C.; Tizzani, P.; Tizzani, M.; Porrino, G.; Ferreri, E.; Busso, V.; et al. Lung ultrasound integrated with clinical assessment for the diagnosis of acute decompensated heart failure in the emergency department: A randomized controlled trial. Eur. J. Heart Fail. 2019, 21, 754-766. [CrossRef]

29. Pascual-Figal, D.A.; Pérez-Martínez, M.T.; Asensio-Lopez, M.C.; Sanchez-Más, J.; García-García, M.E.; Martinez, C.M.; Lencina, M.; Jara, R.; Januzzi, J.L.; Lax, A. Pulmonary Production of Soluble ST2 in Heart Failure. Circ. Heart Fail. 2018, 11, e005488. [CrossRef]

30. Grasselli, G.; Zangrillo, A.; Zanella, A.; Antonelli, M.; Cabrini, L.; Castelli, A.; Cereda, D.; Coluccello, A.; Foti, G.; Fumagalli, R.; et al. Baseline Characteristics and Outcomes of 1591 Patients Infected with SARS-CoV-2 Admitted to ICUs of the Lombardy Region, Italy. JAMA-J. Am. Med. Assoc. 2020, 323, 1574-1581. [CrossRef] [PubMed]

31. Zizzo, G.; Cohen, P.L. Imperfect storm: Is interleukin-33 the Achilles heel of COVID-19? Lancet Rheumatol. 2020, 2, e779-e790. [CrossRef]

32. Villacorta, H.; Maisel, A.S. Teste com ST2 solúvel: Um biomarcador promissor no tratamento da insuficiência cardíaca. Arq. Bras. Cardiol. 2016, 106, 145-152. [PubMed]

33. Colbert, R.; Mital, R.; Marston, N. Biomarkers in heart failure with preserved ejection fraction. Card. Biomark. Case Stud. Clin. Correl. 2016, 24, 357-365.

34. Pascual-Figal, D.A.; Manzano-Fernández, S.; Boronat, M.; Casas, T.; Garrido, I.P.; Bonaque, J.C.; Pastor-Perez, F.; Valdés, M.; Januzzi, J.L. Soluble ST2, high-sensitivity troponin T- and N-terminal pro-B-type natriuretic peptide: Complementary role for risk stratification in acutely decompensated heart failure. Eur. J. Heart Fail. 2011, 13, 718-725. [CrossRef] [PubMed]

35. Giustino, G.; Croft, L.B.; Stefanini, G.G.; Bragato, R.; Silbiger, J.J.; Vicenzi, M.; Danilov, T.; Kukar, N.; Shaban, N.; Kini, A.; et al. Characterization of Myocardial Injury in Patients With COVID-19. J. Am. Coll. Cardiol. 2020, 76, 2043-2055. [CrossRef] [PubMed]

36. Crnko, S.; Printezi, M.I.; Jansen, T.P.J.; Leiteris, L.; van der Meer, M.G.; Schutte, H.; van Faassen, M.; du Pré, B.C.; de Jonge, N.; Asselbergs, F.W.; et al. Prognostic biomarker soluble ST2 exhibits diurnal variation in chronic heart failure patients. ESC Heart Fail. 2020, 7, 1224-1233. [CrossRef]

37. Hernández-Píriz, A.; Tung-Chen, Y.; Jiménez-Virumbrales, D.; Ayala-Larrañaga, I.; Barba-Martín, R.; Canora-Lebrato, J.; Zapatero-Gaviria, A.; García De Casasola-Sánchez, G. Usefulness of lung ultrasound in the early identification of severe COVID-19: Results from a prospective study. Med. Ultrason. 2021, 10. [CrossRef]

38. Torres-Macho, J.; Sánchez-Fernández, M.; Arnanz-González, I.; Tung-Chen, Y.; Franco-Moreno, A.I.; Duffort-Falcó, M.; Beltrán-Romero, L.; Rodríguez-Suaréz, S.; Bernabeu-Wittel, M.; Urbano, E.; et al. Prediction accuracy of serial lung ultrasound in COVID-19 hospitalized patients (Pred-echovid study). J. Clin. Med. 2021, 10, 4818. [CrossRef] [PubMed] 